\title{
for drug co-encapsulation
}

4 Mohamed ZAYED ${ }^{1}$, Corine TOURnE-PETEILH* ${ }^{*}$, Michel RAMONDA ${ }^{4}$, Gildas RETHORE ${ }^{3}$, Pierre WEISS $^{3}$, Jean MARTINEZ ${ }^{2}$, Gilles SUBRA², Ahmad MEHDI ${ }^{1}$, Jean-Marie DEVOISSELLE $^{1}$, Philippe LEGRAND ${ }^{1}$

${ }^{1}$ Institut Charles Gerhardt Montpellier, UMR 5253 CNRS-UM-ENSCM, Place Eugène Bataillon, 34095 Montpellier Cedex 5, France

92 Institut de Biomécules Max Mousseron, UMR 5247 UM-CNRS- ENSCM, Faculté de Pharmacie, 15 Av. Charles Flahault BP 14 491, 34093 Montpellier Cedex 5, France

${ }^{3}$ Inserm, U1229, Regenerative Medicine and Skeleton Research, RMeS, Nantes, France - Université de Nantes, UFR Odontologie, Nantes, France - CHU Nantes, PHU 4 OTONN, Nantes, France.

${ }^{4}$ Centrale de Technologie en Micro et nanoélectronique, Université Montpellier, 860 rue de Saint Priest, 34097 Montpellier, France

\section{Abstract}

Combined therapy is a global strategy developed to prevent drug resistance in cancer and infectious diseases. In this field, there is a need of multifunctional drug delivery systems able to co-encapsulate small drug molecules, peptides, proteins, associated to targeting functions, nanoparticles. Silylated hydrogels are alkoxysilane hybrid polymers that can be engaged in a sol-gel process, providing chemical cross linking in physiological conditions, and functionalized biocompatible hybrid materials.

22 In the present work, microgels were prepared with silylated (hydroxypropyl)methyl cellulose (Si23 HPMC) that was chemically cross linked in soft conditions of $\mathrm{pH}$ and temperature. They were 
prepared by an emulsion templating process, water in oil $(\mathrm{W} / \mathrm{O})$, as microreactors where the condensation reaction took place.

The ability to functionalize the microgels, so-called FMGs, in a one-pot process, was evaluated by grafting a silylated hydrophilic model drug, fluorescein (Si-Fluor), using the same reaction of condensation. Biphasic microgels (BPMGs) were prepared to evaluate their potential to encapsulate lipophilic model drug (Nile red). They were composed of two separate compartments, one oily phase (sesame oil) trapped in the cross linked Si-HPMC hydrophilic phase.

The FMGs and BPMGs were characterized by different microscopic techniques (optic, epifluorescence, Confocal Laser Scanning Microscopy and scanning electronic microscopy), the mechanical properties were monitored using nano indentation by Atomic Force Microscopy (AFM), and different preliminary tests were performed to evaluate their chemical and physical stability.

Finally, it was demonstrated that it is possible to co-encapsulate both hydrophilic and hydrophobic drugs, in silylated microgels, that were physically and chemically stable. They were obtained by chemical cross linking in soft conditions, and without surfactant addition during the emulsification process. The amount of drug loaded was in favor of further biological activity. Mechanical stimulations should be necessary to trigger drug release.

Key words: Microgels, Sol-Gel, alkoxysilane functionalization, co-encapsulation.

\section{Introduction}

Combined therapies gather a wide field of applications where drugs have to be co-encapsulated, to overcome drug resistance in cancer treatments (Borcoman, Le Tourneau, 2016; Bradshaw, Sobel, 2016; Teo, et al., 2016), infectious diseases (Le Douce, et al., 2016; Bento da Silva, et al., 2016), and surgical diseases (Morgan et al., 2016), or to combine growth factor action in tissue regeneration (Subbiah, et al., 2015). Targeted delivery or theranostic approaches could also be combined with 
Reineke, 2011). So, there is a potential and challenging benefit to design multimodal injectable drug delivery systems embedding complementary activities and/or combining cell surface functions such as ligands, adhesion molecules, cytokines, growth factors. One of the limitations of these approaches is to take into account all together the therapeutic goals as well as the formulation constraints. Another limitation is the multi-step building chemistry process used to functionalize nano/ microparticles. Such designs need multi-process and multi-functional approaches. In this context, there is a need of new functionalized polymers to embed different complementary activities, which respects biocompatibility, but also reduces the time, the cost, and the environmental impact of the manufacturing process.

Microgels are defined as microparticles of chemical (covalent links) or physical (weak interactions) cross linked hydrogels. They consist of three-dimensional polymer network, able to swell or shrink under large amount of water exchanges. They could be responsive to the changes in $\mathrm{pH}$, temperature or other physiological stimuli, suitable for drug controlled release. They are basically obtained and stabilized by hydrogen-bond or electrostatic interactions in alginate (Matalanis, et al., 2011), chitosan (Dang, et al., 2016), and pectine. (Marquis, et al., 2014) Nevertheless for some applications, chemical cross linking could be recommended to improve the mechanical properties, stabilize the drug interactions and prevent burst release effects. (Zhao, 2013)

For decades hydrogels have been investigated to design delivery systems for Active Pharmaceutical Ingredients (APIs). They are composed of natural or synthetic polymers that could be cross linked by chemical covalent bonds, or physically via non-covalent links, in order to form a network able to control the API delivery. (Pagels, 2015) Physical cross linked hydrogels are usually obtained by weak ionic interactions, in ionisable polymers such as hyaluronic acid, pectin, chitosan and alginate. (Hamidi, et al., 2008) Chemical hydrogels are obtained by covalent cross linking most of the time using polymers modified with methacrylate derivatives (Hamidi, et al., 2008; Jagadeesan, et al., 2011; Nguyen, et al., 2015; Cha, et al., 2014; Bachman, et al., 2015; Glaubitz, et al., 2014), or using cross linking reagents such as gluteraldehyde, carbodiimides, or di-halo species (Pagels, 
Prud'homme, 2015). The presence of such species and/or the formation of bypass products during the cross linking reaction, could interact with biological environment and disturb the cell metabolism.

Recently, a new family of hydrogels were functionalized with alkoxysilane groups, allowing chemical cross linking, based on the hydrolysis condensation reaction of - $\mathrm{Si}(\mathrm{OR})_{3}$ into stable $\mathrm{Si}-\mathrm{O}-\mathrm{Si}$ covalent links. Thus, silylated (hydroxypropyl)methyl cellulose (Si-HMPC) were developed as biocompatible and injectable silylated hydrogels (Bourges, et al., 2002a, 2002b; Echalier, et al., 2016; Vinatier, et al., 2009; Vinatier, et al., 2007; Vinatier, et al., 2009; Liu, et al., 2014). Interestingly, bisilylated poly(ethylene glycol) (Si-PEG) was also synthesized and exhibits relevant cytotoxicity results (Echalier, et al., 2016). Then, Si-hydrogels open up a wide range of applications including bone repair (Zhang, et al., 2016; Struillou, et al., 2013), cartilage tissue engineering (Buchtova, et al., 2013), and treatment of chronic colonic diseases (Moussa, et al., 2017). Echalier et al. has developed Si-peptides hydrogels leading to biological responsive hydrogels such as adhesive peptide sequence RGD, peptide sequence having antibacterial activity (Echalier, et al., 2016) or collagen inspired (Echalier, et al., 2017). (Jagadeesan, et al, 2011) Recently Busatto et al. proposed oil in hyaluronic acid microgels for such as Pickering emulsions. (Marquis, et al., 2016)

To the best of our knowledge, there is no example of microgels obtained with silylated hydrogels, and little examples of chemical microgels bearing lipidic compartments for co-encapsulation of complementary APIs. Jagadeesan et al. have trapped hexadecane droplets in an aqueous phase containing a monomer n-isopropylacrylamide, a cross linker $\mathrm{N}, \mathrm{N}$ '-methylenebis(acrylamide) a surfactant Brij 35), and a photoinitiator 2,2'-azobis (2-methylpropionamidine) dihydrochloride. enzymatic trigger release of an hydrophobic drug (progesterone). (Busatto, et al., 2017) Whatever the emulsification strategies, encapsulation of lipophilic components remains a complex task because of the stabilization of the $\mathrm{O} / \mathrm{W}$ primary emulsion (Matalanis, et al., 2013) and may require approaches 
105 The aim of this work was to (i) demonstrate the ability to produce microgels using silylated HPMC 106 by the way of the Sol-Gel reaction of condensation of the -SiOR functions, (ii) to functionalize them, with a model function, using the same Sol-Gel reaction in a one-pot process (FMGs), and (iii) to generate biphasic microgels (BPMGs) containing lipophilic compartments intended to formulate poorly soluble drugs. Model drugs were used in the present work, Nile Red (NR) as lipophilic and silylated Fluorescein (Si-Fluor) as chemically linked function.

\section{Materials and methods}

\subsection{Materials}

115

\subsection{Preparation of the functionalized microgels (FMGs)}

The W/O emulsion was obtained after the addition of the Si-HPMC solution into the oily phase. It was added to the sesame oil with a controlled feeding rate of $0.1 \mathrm{~mL} / \mathrm{min}$, using a syringe pump apparatus (HARVARD APPARATUS pump 33), at a ratio of 1/10 v:v. The dispersion was done 
under high shearing stress using a disperser (Disperser T18 digital ULTRA-TURRAX), with a $10 \mathrm{~mm}$ rotor-stator, IKA ${ }^{\circledR}$-WERK GmbH \& Co. KG (Staufen, Germany) at a speed of $5000 \mathrm{rpm}$ in ice for $20 \mathrm{~min}$. Then, the temperature was increased to $45^{\circ} \mathrm{C}$ and maintained for $10 \mathrm{~min}$. The dispersion was left to stand overnight at room temperature under mild stirring $(500 \mathrm{rpm})$ for aging. Finally, FMGs were washed with $\mathrm{H}_{2} \mathrm{O}$ /ethanol (1/1 v:v) and stabilized with $0.05 \%$ Lutrol $\mathrm{F}-127$, an injectable surfactant, to facilitate the suspension handling.

The aqueous phase was composed of $1 \mathrm{~mL}$ of Si-HPMC solution 3 wt.\%, that was neutralized with 2[4-(2-hydroxyethyl)piperazin-1-yl]ethane sulfonic acid buffer (HEPES, PM = 238,3 g/mol) at $\mathrm{pH}$ 3.5 , with a volume ratio of 1:2 (Vinatier, et al., 2007). The Si-HPMC hydrogel was functionalized by Si-Fluor ethanolic solution that was added to the Si-HPMC phase, and kept in ice. The mixture was diluted two times with fresh sesame oil to reduce the aggregation of the microgels.

\subsection{Preparation of the biphasic microgels (BPMGs)}

A $\mathrm{O} / \mathrm{W}$ primary emulsion was obtained by dispersing the sesame oil solution of NR (Ultra Turrax, $5000 \mathrm{rpm}$ for $1 \mathrm{~min}$ ) in the $\mathrm{Si}-\mathrm{HPMC}$ solution with a volumic ratio of $5 \%$. The Si-HPMC continuous phase was then neutralized and maintained in ice. To prepare the BPMGs, the $\mathrm{O} / \mathrm{W}$ primary emulsion was dispersed in the sesame oil continuous phase $(\mathrm{O} / \mathrm{W} / \mathrm{O})$ with a syringe pumps apparatus (HARVARD APPARATUS pump 33). The feeding rate was optimized in the range of 0.1 to 1 $\mathrm{mL} / \mathrm{min}$. The final volume ratio was $1 / 10$. After this step, the process was the same as for FMGs.

\subsection{Interfacial tension and rheological properties}

The surface and interfacial tension were measured with a Krüss tensiometer K100 using the Wilhelmy plate method. The experiments were performed at room temperature $\left(20-25^{\circ} \mathrm{C}\right)$ in aqueous solution of Si-HPMC in the range 0.03 wt. $\%$ and $3.75 \times 10^{-6}$ wt. $\%$. 
159 The dynamic viscosity of the continuous phase was measured with a coaxial cylinder rheometer, 160 Rheomat RM 200 (Lamy, France) at $7.7^{\circ} \mathrm{C}, 21.0^{\circ} \mathrm{C}, 38.0^{\circ} \mathrm{C}$ and $48.0^{\circ} \mathrm{C}$. The velocity, $\omega$, was 161 continuously increased from 64.6 to $1290.0 \mathrm{~s}^{-1}$. The force exerted on the cylinder (diameter $30 \mathrm{~mm}$ ) 162 was measured and converted to a shear stress.

\subsection{FMGs and BPMGs Characterizations}

The optical characterizations were performed by Epi-fluorescence microscopy on an inverted EVOS ( FL, Life Technologies, laser scanning confocal microscope (LSCM) was done on a Confocal Leica SP8. The scanning electronic microscopy (SEM) was done on a MEB FEI Quanta 200 environmental, for the observation of the as-synthesized microgels, as well as the freeze-dried samples.

The size distribution of the FMGs, BPMGs and oil droplets were achieved with the Image J program. The size was measured for at least 100 items as possible, with $n \geq 20$, and by using at least two different photos. The size distribution was graphically expressed in percentage number of particles and fitted by the Log Normal function were $x_{c}$ gave the mean size and $w$ the standard deviation (OriginPro 8.1).

\subsection{Nano indentation and topographic analysis by AFM}

Study of the nanomechanical properties of the FMGs and BPMGs and the scanning topographically of its surface was done by atomic force microscope (AFM D3100 Bruker Instruments), with a Nanoscope 3A Quadrex (electronics device) in which the mode contact was used without scanning (fixed point to perform approach retract curve). The tip has a platinium coverage (around $10 \mathrm{~nm}$ ) and on the apex of a lever there are point probe nanosensors with a nominal spring constant $0,4 \mathrm{~N} / \mathrm{m}$ (measured with thermal tune). The tip is mounted on a tip-holder suitable for measurement on liquid environment. The measurement of the Force, $F(\mathrm{~N})$, to indentation distance, $\delta(\mathrm{m})$, were done on hydrated microgels, whose surface was totally dried before applying the AFM to prevent attachment 
of the microgels to the tip of the cantilever. The Young's elastic modulus, $\mathrm{E}(\mathrm{Pa})$, was

calculated after linearization of the equation of the Sneddon model:

$$
F=\frac{2}{\pi} \frac{E}{\left(1-v^{2}\right)} \tan (\alpha) \delta^{2}
$$

with the Poisson's ratio, $v=0.5$, the half angle of the indenter, $\alpha=35^{\circ}$. The topographic observations were done after drying the samples under air overnight.

\subsection{Determination of the amount of Si-Fluor linked to cross linked Si-HPMC}

The amount of Si-FITC which was covalently linked, $\mathrm{C}_{\mathrm{L}}$, was evaluated in bulk Si-HPMC gels, at different initial concentrations $\left(\mathrm{C}_{\mathrm{i}}\right)$. The bulk Si-HPMC gels were with $0.100 \mathrm{~mL}$ of a solution of $\mathrm{Si}$ HPMC 3 wt.\% that was neutralized by HEPES pH 3.5. After 2 days of aging, the bulk gels were washed consequently with two saline solutions. Firstly, the bulk gels were washed with Phosphate Buffer Solution (PBS) at $\mathrm{pH} 7.4$ and room temperature, to remove the free Si-FITC not chemically linked or weakly adsorbed to the Si-HPMC $\left(\mathrm{C}_{\mathrm{Ads}}\right)$. Secondly, the gels were soaked in $\mathrm{NaOH} 0.2 \mathrm{M}$ $\mathrm{pH}$ 10. These hydrolytic conditions led to the cleavage of the Si-O-Si bonds, and allowed to extract the chemically linked species or the one less adsorbed but not extracted in PBS $\left(\mathrm{C}_{\mathrm{H}}\right)$. Then, a full extraction was done by Dimethyl Sulfoxide $\left(\mathrm{C}_{\mathrm{DMSO}}\right)$. The amount of FITC extracted were determined by spectrofluorimetry (spectrofluorimeter RF 5000 , Shimadzu) at $\lambda_{\text {ex }}=490 \mathrm{~nm}$ and $\lambda_{\mathrm{em}}=515 \mathrm{~nm}$. The concentration of strongly linked species $\left(\mathrm{C}_{\mathrm{L}}\right)$ was calculated according to the following equation:

$$
\mathrm{C}_{\mathrm{L}}=\mathrm{C}_{\mathrm{i}}-\left(\mathrm{C}_{\mathrm{Ads}}+\mathrm{C}_{\mathrm{DMSO}}+\mathrm{C}_{\mathrm{H}}\right)
$$

\subsection{Chemical and physical stability of FMGs and BPMGs}

The stability of FMGs and BPMGs was evaluated in different media and followed by means of dosage of Nile Red (NR) and fluorescein, microscopic observations and their mechanical properties. $20 \mathrm{mg}$ of FMGs or BPMGs were introduced into $50 \mathrm{~mL}$ of each medium, namely (i) in physiological simulated media, that is in Phosphate Buffer Saline (PBS) $66 \mathrm{mM}$ at $\mathrm{pH} 7.4$ and in $\mathrm{HCl}$ medium at 
$\mathrm{pH} 1.5$ for 40 days at $37^{\circ} \mathrm{C}$, (ii) in alkaline hydrolytic conditions in $0.2 \mathrm{M} \mathrm{NaOH}$ at $\mathrm{pH} 10$ for 1 hour at room temperature, and (iii) in Dimethyl Sulfoxide (DMSO) for full extraction.

Samples were taken at different times and measured on the spectrofluorimeter (RF 5000, Shimadzu), using $\lambda_{\mathrm{ex}}=551 \mathrm{~nm}$ and $\lambda_{\mathrm{em}}=609 \mathrm{~nm}$ to detect the $\mathrm{NR}$, and $\lambda_{\mathrm{ex}}=490 \mathrm{~nm}$ and $\lambda_{\mathrm{em}}=515 \mathrm{~nm}$ for 213 fluorescein.

\section{Results and discussion}

\subsection{Preparation of the microgels}

The microgels were obtained using an emulsion-templating method that produces water in oil droplets, acting as microreactors, where the cross linking reaction could take place. As previously shown by P. Weiss and co-workers, the cross linking of Si-HPMC was done in soft conditions, with a maximum rate of condensation of the silanolate functions into siloxane bridges at $\mathrm{pH} 7.4$ and a temperature of $45^{\circ} \mathrm{C}$ (Fatimi, Tassin, 2009). As suggested by the authors, the gelation time increased as a function of temperature which has a catalytic action on the condensation reaction. They suggest also that, at high temperature $\left(45^{\circ} \mathrm{C}\right.$ or higher), additional mechanisms, such as the association of the hydrophobic zones in the polysaccharide chain, can reinforce the essential network formation process.

This reaction was adapted to occur in the microreactors, containing the Si-HPMC hydrogel solution, to separate in time the dispersion of the water phase and the reaction of condensation. The whole optimizations were done on the preparation of the BPMGs. Scheme 1 summarizes the principal of the formation of the functionalized microgels with the silylated fluorescein (FMGs) and the biphasic microgels (BPMGs), thanks to the critical physico-chemical parameters involved in the process. 
236 First of all, the W/O emulsion formed a microenvironment at which the condensation reaction could 237 take place. This step was common to both the preparation of the FMGs and the BPMGs, and was the critical step to obtain the microgels. Indeed, it required the emulsion stability and the kinetic control of the condensation reaction. The first point was insured by the unique intrinsic interfacial properties of HPMC to stabilize the W/O emulsion. Indeed, aqueous solutions of Si-HPMC and HPMC exhibited similar interfacial liquid/air activities, $\Gamma$, critical aggregation concentrations, $C A C$, and Gibbs surface areas, $A_{\text {Gibbs }}$ (Table 1) (Wollenweber, et al., 2000). The mean interfacial tensions, $\gamma_{\mathrm{o} / \mathrm{w}}$, between water and sesame oil were measured at $35.2 \mathrm{mN} / \mathrm{m}$ and was significantly decreased in presence of $\mathrm{Si}-\mathrm{HPMC}$ at $14.8 \mathrm{mN} / \mathrm{N}$, allowing to stabilize the emulsion interface. Then, it was possible to obtain stable emulsions without addition of extra surfactant or other chemical modification to decrease the interfacial tension (Figure 1A, D).

Secondly, because of the kinetic aspect of the condensation reaction, the emulsification step has to be carefully separated from the cross linking initiation during the preparation process. Indeed, as the $\mathrm{pH}$ neutralization lead to the condensation of silanolate groups, even at room temperature, and form the three dimensional network in about 15 min (Fatimi, Tassin, 2009), the W/O preparations were done below $10^{\circ} \mathrm{C}$, to delay the condensation reaction. Moreover, high shearing rate dispersion was applied to favor the formation of the microreactors during the water phase dispersion. Hence, the condensation reaction led to a strong increase of the dynamic viscosity, $\eta_{\text {disp }}$, of dispersed aqueous phase, from 2000 Pa.s $\left(\mathrm{pH} 12-13,20^{\circ} \mathrm{C}\right)$ to $20000 \mathrm{~Pa} . \mathrm{s}\left(\mathrm{pH} 7,45^{\circ} \mathrm{C}\right)$, while it tend to slightly decrease in the continuous phase from $\eta_{\text {cont }}=69$ Pa.s to 30 Pa.s, respectively. In these conditions the ratio $\eta_{\text {disp }} / \eta_{\text {cont }}>>1$, so that a high shearing stress was necessary to split the dispersed aqueous phase into microdroplets before the cross linking occurred. When the temperature was increased up to $45^{\circ} \mathrm{C}$, the condensation reaction was induced.

Figure 1B shows that the formation of the microgels was only done in presence of the siloxane functions, after induction of the condensation by tuning both the $\mathrm{pH}$ and the temperature. Si-HPMC precipitations (Figure 1C) may appear even without these stimulations, but with no control of the 
morphology. Furthermore, the formation of the $\mathrm{Si}-\mathrm{O}-\mathrm{Si}$ bridges contributed to the stability of the W/O emulsion, as no droplets could be found at the end of the process when native HPMC was used (Figure1E).

Finally, the feeding rate of the water phase was optimized because it was found to be a limiting factor to obtain spherical, non-aggregated microgels with controlled size distribution. The optimized microparticles were obtained for a feeding rate of $0.1 \mathrm{~mL} / \mathrm{min}$ of $\mathrm{O} / \mathrm{W}$ emulsion added to the oily

\subsection{Evaluation of the functionalization potential of the microgels (FMGs)}

Fluorescein isothiocyanate modified by silanization (Si-Fluor) (Echalier, et al., 2016) was chemically linked to the free siloxanes functions of the Si-HPMC polymer chains of the microgels during the cross linking reaction, in a one-pot process. It could be noticed that no toxic catalyzer such as sodium fluoride (usually applied to catalyze sol-gel reactions) was used in this process as it could be necessary for the linking of Si-Fluor in Si-PEG hydrogels even at low concentration respecting the cell viability (Echalier, et al., 2016). That represents a great advantage against cytotoxicity and purification steps.

Different consecutive extraction steps were applied to the bulk Si-HPMC gels in order to estimate the maximum amount of Si-FITC, $\mathrm{C}_{\mathrm{L}}$, which could be strongly linked to the silylated polymer (Table 2). It was calculated depending on the equation $\mathrm{C}_{\mathrm{L}}=\mathrm{C}_{\mathrm{i}}-\left(\mathrm{C}_{\mathrm{Ads}}+\mathrm{C}_{\mathrm{DMSO}}+\mathrm{C}_{\mathrm{H}}\right)$. The amount of covalently linked Si-FITC was obtained by subtracting from the initial concentration of Si-FITC $\left(\mathrm{C}_{\mathrm{i}}\right)$, the sum of the free Si-FITC weakly adsorbed to the Si-HPMC $\left(\mathrm{C}_{\mathrm{Ads}}\right)$, the chemically linked less stable species $\left(\mathrm{C}_{\mathrm{H}}\right)$ and the amount extracted by DMSO $\left(\mathrm{C}_{\mathrm{DMSO}}\right)$. DMSO is an organic solvent that could solubilize all the species present, without any effect on the Si-O-Si covalent link. 
288 A maximum of $1.12 \mu \mathrm{g}$ of Si-FITC per gram of Si-HPMC was covalently linked, as no Si-FITC could be 289 detected in the PBS medium, meaning that the whole Si-FITC species added were totally linked. This represents about $70 \mu$ mole of FITC per 1 mole of HPMC, taking into account a total of siloxanes functions available in the hydrogel estimated to $0.6 \mathrm{wt} \%$. (Fatimi, et al., 2008)

These amounts are in good agreement with biological activities usually expected or observed, and comprises in the pM to $\mu \mathrm{M}$ range of concentrations in interactions (Popp, et al., 2017), cells adhesion (Wu et al., 2017), cancer therapy (Rui, et al., 2017), or antibody recognition. (Colombo et al., 2016)

\subsection{Biphasic microgels (BPMGs) preparation and Nile Red loading efficiency}

BPMGs were produced by following a two steps $\mathrm{O} / \mathrm{W} / \mathrm{O}$ emulsion templating process. The W/O emulsion templating step was the same as for the production of the FMGs. Here we describe the formation of the primary emulsion $\mathrm{O} / \mathrm{W}$ that was used as a reservoir for the lipophilic model drug. Figure 3 shows a microscopic description of a homogeneous primary $\mathrm{O} / \mathrm{W}$ emulsion. The size distribution of the oil droplets was sharpened and centered to $4.0 \mu \mathrm{m}$ with a STD of 0.15 determined by the $\log$ normal fitting curve. After freeze drying, the oil droplets were still trapped in the SiHPMC matrix (Figure 3D) in the same size range observed in primary emulsion $\mathrm{O} / \mathrm{W}$. These results gave an evidence of the emulsion stability using the interfacial activity of the HPMC, that simplify the chemical composition of continuous phase, usually requiring hydrophilic surfactant (Jagadeesan, et al., 2011) or nanoparticles in Pickering O/W emulsions. (Marquis, et al., 2016)

SEM observations of the as-synthesized and freeze-dried BPMGs gave the proof that the oil droplets were still trapped inside the Si-HPMC network (Figure 4) as it was observed in the freeze dried O/W primary emulsion (Figure 3). The oil droplets were uniformly distributed in whole volume of the BPMGs as shown by LSCM observations (Figure 4C). The internal texture of the Si-HPMC matrix exhibited fibers of the cellulosic network, that had a diameter in the range of $10 \mathrm{~nm}$. It formed a porous network of a mean ladder distance of $20 \mathrm{~nm}$ determined on the topographic picture obtained by AFM (Figure 4D). 
314 Nile red (NR) was chosen as a model drug because its $\log \mathrm{P}$ value comprises between 3.0 and 5.0 315 (Küchler, et al., 2009; Merian, et al., 2012; Weber, et al., 2014) which is the value of 30 to $40 \%$ of 316 the commercialized APIs (lipophilic to low lipophilic) covering a wide range of applications. (Pyka, 317 et al., 2006; Pallicer, et al., 2014) Sesame oil was selected because of its good solubilization power 318 for poorly soluble drugs (Ahmed, Hassan, 2007). It is injectable for subcutaneous or intramuscular (Rowe, et al., 2009) NR was directly loaded in the primary $\mathrm{O} / \mathrm{W}$ emulsion up to saturation in the sesame oil, with a maximum of $25.0 \mu \mathrm{g} / \mathrm{mL}$ (Table 3). Over this concentration NR diffused in the SiHPMC water phase and BPMGs formation was not possible anymore. This was ascribed to an increase of the microviscosity in the cellulosic hydrogel, due to the interactions with NR that disrupt the first layer of hydration (Katzhendler, et al., 2000). The size distribution of the oil droplets was also affected by the NR loading.

\subsection{Mechanical properties of the FMGs and the BPMGs}

The cross linking efficiency was evaluated by measuring the nanomechanical properties of the FMGs and the BPMGs by the means of atomic force microscopic nano indentation (Figure 5). In addition to the measurement of the hardness value, the depth-sensing indentation has been routinely used to extract the elastic properties of the specimen, with known indenter geometry and material properties. (Poon, et al., 2008) According to Sneddon's equation, the elastic modulus E ( $\mathrm{kPa}$ ) was calculated to give an indication of the hardness of the samples.

The elastic modulus of the FMGs was found to be $5.9 \mathrm{kPa}$ which is two times higher than the value previously observed for cylindrical gels $\mathrm{Si}$-HPMC-Si $(\varnothing \approx 2.4 \mathrm{~cm})$ that was determined at $2.96 \mathrm{kPa}$ by measuring their compressive modulus. (Rederstorff, et al., 2011) This confirmed the cross linking efficiency inside the microdroplets of the Si-HPMC W/O emulsion. The elastic modulus of the BPMGs was significantly increased up to $144 \mathrm{kPa}$ due to the presence of the oily phase trapped inside the cross linked Si-HPMC hydrogel. There is a great increase in the elastic modulus which is an indication of its hardness. Sekine et al. reported that the hardness and stability of o/w/o multiple 
emulsion was enhanced by increasing the weight ratio of the inner $\mathrm{O} / \mathrm{W}$ emulsion. (Sekine, et al., 2000)

These values match with elastic modulus of 2 to $204 \mathrm{kPa}$, that can be recorded on gelatin methacrylic microgels $\leq 10$ wt $\%$ with sizes in the same range $(<5-150 \mu \mathrm{m})$ and depending on the formulation parameters. (Cha, et al., 2014; Nguyen, et al., 2015) As comparison, living cells exhibit elastic modulus comprised in a range of $0.2-200 \mathrm{kPa}$ that depends on the differentiation stage, growth, adhesion. (Kuznetsova, et al., 2007) Both the size and elastic modulus of the FMGs and the BPMGs were comparable to those of eukaryotic living cells. This allows good expectations for their coexistence in confined physiological environment, such as injectable or implantable scaffolds.

\subsection{Chemical and physical stability of FMGs and BPMGs}

Polysaccharide-based microgels with high water content, controllable particle size and high stability have been widely studied as candidates for drug release and delivery. Different release mechanisms of drugs could be observed from hydrogels. (Hamidi, et al., 2008) The most common mechanism is passive diffusion, meaning free diffusion into/out of the hydrogel network. It depends mainly on the molecular size and the mesh size of the hydrogel network, and follows the Fick's first law of diffusion. Typical porosities expressed in mesh size are reported for biomedical hydrogels in the range of 5 to $100 \mathrm{~nm}$ (in their swollen state). After comparison, it could be related to the dimensions observed on the ladder size of the Si-HPMC network (Figure 4D), which are much larger than most of small molecule drugs.

The release of the model drugs from BPMGs was evaluated in a phosphate buffer saline (PBS) at pH 7.4 and $37^{\circ} \mathrm{C}$ to mimic standard physiological conditions. After a period of 40 days, no diffusion of fluorescein was observed indicating a stable linkage to the Si-HPMC (Figure 6). No diffusion in the external medium was either observed for the Nile Red. The detection threshold was found to be in the range of 0.5 picoM both in the PBS buffer and in DMSO. The intensities of fluorescence were in the same range from $1 \mu \mathrm{M}$ and $25 \mu \mathrm{M}$ in both solvents. The maximum concentration of NR that could be released in the PBS was about $20 \mu \mathrm{M}$. So, there was not a problem of detection of the NR in the aqueous medium. Moreover, some accumulation of NR was observed in the Si-HPMC phase, as it can be seen in Figure 7 (B, D, F). 
This was ascribed to a partition with the oil droplets, as described by Busatto et al. with progesterone encapsulated in oil droplets trapped in microgels based on methacrylated hyaluronic acid. (Busatto, et al., 2017) The NR behavior was hypothesized to adsorbed to the hydrophobic isopropyl and methyl parts of HPMC. It is important to notice that this NR retention is not due to its poor water solubility but rather due to the physical properties of the microgels. In fact, NR encapsulated in lipid nanoparticles (Delmas et al.,2012) and either in nanoemulsions dispersed in chitosan hydrogel (Delmar et al., 2016) showed sustained but complete releases.

373 After 17 days of incubation, however, microscopic observations exhibited a loss of the spherical structure and a release of the oil droplets, accompanied by a loss of the mechanical properties, oil droplets were released leaving empty skin structures of cross linked microgels (Figure 7C).

376 A full extraction with an organic solvent, DMSO, allowed the extraction of the fractions of fluorescein and NR supposed to be adsorbed by weak interactions in the hydrogel. DMSO did not have hydrolytic action on the Si-O-Si chemical bonds, but is able to solubilize all the components of the BPMGs namely sesame oil, Nile Red, fluorescein and HPMC (Cao, et al., 2015). This resulted in the extraction of $85 \pm 7$ wt.\% of the total initial amount of fluorescein. This means that about $15 \%$ of the fluorescein was still linked to Si-HPMC matrix. About $70 \pm 7$ wt.\% of the initial amount of NR were also extracted (Figure $6)$.

Extreme values of $\mathrm{pH}$ (acidic $\mathrm{pH} 1.5$ and alkaline $\mathrm{pH}$ 10.0) were applied to the BPMGs in order to evaluate the chemical stability of the Si-O-Si bridges (Brinker, Scherer, 1990). The acidic conditions did not affect the release. It was correlated to the strengthening of the mechanical properties of both BPMGs and FMGs (Figure 7). This behavior could be related to self hardening process due to the condensation of silanolates into siloxane bridges, which is promoted at low $\mathrm{pH}$ values (Bourges, et al., 2002b) (Brinker \& Scherer, 1990).

However, in alkaline conditions, $25 \pm 5 \mathrm{wt} . \%$ of the total amount of Si-Fluor and $15 \pm 3 \mathrm{wt} . \%$ of the total amount of NR could be extracted. The release of these fractions was then subjected to the degradation of the Si-O-Si bonds. A fraction of the Si-Fluor species were released by hydrolysis of 
392 the Si-O-Si bond. The oil droplets trapping the NR could be released by the hydrolytic degradation of 393 the Si-O-Si bonds involved in the Si-HPMC network. Actually, a good stability of the linkage of Si394 Fluor to the Si-HPMC hydrogel was observed, which will be suitable for further biological 395 functionalization of the FMGs and the BPMGs.

396 These results showed a strong retention of the model drugs, Si-Fluor and NR, in simulated 397 physiological conditions. Therefore, the hydrophobic drug control release should be obtained under 398 mechanical stimulation.

\section{Conclusion}

400 The preparation and the functionalization of microgels made of Si-HPMC were obtained by the 401 unique condensation reaction of alkoxysilane functions in physiological conditions of temperature 402 and $\mathrm{pH}$. An emulsion templating process was applied using only the interfacial properties of HPMC 403 without the use of any surfactant.

404 The size distributions of the microgels are relevant with injections in implant sites for intra-articular, sub405 cutaneous.

406 The model function Si-Fluor was chemically linked with a good stability and in the range of amounts 407 compatible with a further biological activity.

408 Biphasic microgels were obtained with a double emulsion process for the loading of a lipophilic model drug in oil droplets trapped in the hydrogel core. The oil droplets could be released after incubation in physiological conditions for 17 days. Mechanical stimulation will be needed to trigger further drug release.

412 Finally, it was shown that the alkoxysilane modified hydrogels represents a promising modular 413 strategy that open a new way to design and to multi-functionalize drug delivery systems in limited preparation steps.

\section{Authors contribution}


M. Zayed, PhD fellowship, did the full preparation and characterizations of the materials. Prof. P. Weiss synthesized and provided the silylated HPMC. Prof. G. Subra and Prof. A. Mehdi synthesized and provided the silylated fluorescein. M. Ramonda performed the AFM measurements and Elastic modulus calculations. Prof. P. Legrand, Prof. J.-M. Devoisselle and Dr C. Tourne-Peteilh supervised the processing and characterizations of the elaboration of the microgels.

421

Acknowledgment: Misr University for Science and Technology (MUST), University of Egypt, for grant of Mr Mohamed Zayed PhD degree. LCSM observations were done on the Technology Facilities for Life Sciences, BioCampus, Montpellier, France.

Corresponding author : Dr C. Tourne-Peteilh, affiliated to University of Montpellier, Departement of Chemistry, ICGM, UMR 5253 CNRS-UM-ENSCM, Faculté de Pharmacie, 15 avenue Charles Flahault, Bât C, 3Et., 34093 Montpellier; email : corine.tourne-peteilh@enscm.fr; tel : +33 (0)4 11759452.

\section{References}

Ahmed, I. S., Hassan, M. A.-E., 2007. In vitro and in vivo evaluation of a fast-disintegrating lyophilized dry emulsion tablet containing griseofulvin. Eur. J. Pharm. Sci. 32, 58-68.

Bachman, H., Brown, A. C., Clarke, K. C., Dhada, K. S., Douglas, A., Hansen, C. E., et al., 2015. Ultrasoft, highly deformable microgels. Soft Matter. 11, 2018.

Bento da Silva, P., de Freitas, E. S., Bernegossi, J., Gonçalez, M. L., Sato, M. R., Leite, C. Q., et al, 2016. Nanotechnology-Based Drug Delivery Systems for Treatment of Tuberculosis-A Review. J. Biomed. Nanotechnol. 12, 241-260.

Borcoman, E., Le Tourneau, C., 2016. Antibody Drug Conjugates: The Future of Chemotherapy ? Curr. Opin. Oncol. 28, 429-436.

Bourges, X., Weiss, P., Coudreuse, A., Daculsi, G., Legeay, G., 2002. General Properties of Silated Hydroxyethylcellulose for Potential Biomedical Applications. Biopolymers. 63, 232-238.

Bourges, X., Weiss, P., Daculsi, G., \& Legeay, G., 2002. Synthesis and general properties of silated(hydroxypropyl)methyl cellulose in prospect of biomedical use. Adv. Colloid Interface Sci. 99, 215-228. 
Bradshaw, C. S., \& Sobel, J. D., 2016. Current Treatment of Bacterial Vaginosis - Limitations and Need for Innovation. Proceedings of the 2015 NIH/NIAID Bacterial Vaginosis Expert Consultation. 214, S14-S20.

Brinker, J. C., \& Scherer, G. W., 1990. Sol-Gel Science - The Physics and Chemistry of Sol-Gel Processing.

Buchtova, N., Rethore, G., Boyer, C., Guicheux, J., Rambaud, F., Valle, K., et al., 2013. Nanocomposite hydrogels for cartilage tissue engineering: mesoporous silica nanofibers interlinked with siloxane derived polysaccharide. J. Mater. Sci. Mater. Med. 24, 1875-1884.

Busatto, C., Labie, H., Lapeyre, V., Auzely-Velty, R., Perro, A., Casis, N., et al., 2017. Oil-in-microgel strategy for enzymatic-triggered release of hydrophobic drugs. J. Colloid Interface Sci. 493, 356-364.

Cao, H., Song, J., Fang, X., 2015. Effect of dimethyl sulfoxide (DMSO) on cellulose solution with high concentration. Adv. Mat. Res. 1095, 329-332.

Cha, C., Oh, J., Kim, K., Qiu, Y., Joh, M., Shin, S. R., et al., 2014. Microfluidics-Assisted Fabrication of

Gelatin-Silica Core-Shell Microgels for Injectable Tissue Constructs. Biomacromolecules. 15, 283-290.

Ciccione, J., Jia, T., Coll, J.-L., Parra, K., Amblard, M., Jebors, S., et al., 2016. Unambiguous and Controlled One-Pot Synthesis of Multifunctional Silica Nanoparticles. Chem. Mater. 28, 885-889.

Colombo, M., Fiandra, L., Alessio, G., Mazzucchelli, S., Nebuloni, M., De Palma, C., et al., 2016. Tumour homing and therapeutic effect of colloidal nanoparticles depend on the number of attached antibodies. Nat. Commun. 7, 13818.

Dang, Q., Liu, C., Wang, Y., Yan, J., Wan, H., Fan, B., 2016. Characterization and biocompatibility of injectable microspheres-loaded hydrogel for methotrexate delivery. Carbohydr. Polym. 136, 516-526.

Delmar, K., Bianco-Peleda, H., 2016, Composite chitosan hydrogels for extended release of hydrophobic drugs, Carbohydrate Polymers, 136, 570-580.

467 Echalier, C., Jebors, S., Laconde, G., Brunel, L., Verdie, P., Causse, L., et al., 2017. Sol-gel synthesis of collagen-inspired peptide hydrogel. Mater. Today. 20, 59-66. 
Echalier, C., Pinese, C., Garric, X., Van Den Berghe, H., Jumas Bilak, E., Martinez, J., et al., 2016. Easy

Synthesis of Tunable Hybrid Bioactive Hydrogels. Chem. Mater. 28, 1261-1265.

Fatimi, A., \& Tassin, J.-F., 2009. Gelation studies of a cellulose-based biohydrogel: Influence of pH, temperature and sterilisation. Acta Biomater. 5, 3423-3432.

473 Fatimi, A., Tassin, J.-F., Quillard, S., Axelos, M. A., Weiss, P., 2008. The rheological properties of silated (hydroxypropyl)methyl cellulose tissue engineering matrices. Biomaterials. 29, 533-543.

475 Glaubitz, M., Medvedev, N., Pussak, D., Hartmann, L., Schmidt, S., Helm, C. A., et al., 2014. A novel contact 476 model for AFM indentation experiments on soft spherical cell-like particles. Soft Matter. 10, 6732.

477 Hamidi, M., Azadi, A., Rafiei, P., 2008. Hydrogel nanoparticles in drug delivery. Adv. Drug Deliv. Rev. 60, $478 \quad 1638-1649$.

479 Jagadeesan, D., Nasimova, I., Gourevich, I., Starodubtsev, S., Kumacheva, E., 2011. Microgels for the 480 Encapsulation and Stimulus-Responsive Release of Molecules with Distinct Polarities. Macromol. Biosci. 11, $481889-896$.

482 Katzhendler, I., Mader, K., Friedman, M., 2000. Structure and hydration properties of (hydroxypropyl)methyl 483 cellulose matrices containing naproxen and naproxen sodium. Int. J. Pharm, 200, 161-179.

484 Kelkar, S. S., Reineke, T. M., 2011. Theranostics: Combining Imaging and Therapy. Bioconjugate Chem. 22, $485 \quad 1879-2198$.

486 Küchler, S., Abdel-Mottaleb, M., Lamprecht, A., Radowskic, M. R., 2009. Influence of nanocarrier type and 487 size on skin delivery of hydrophilic agents. Int. J. Pharm. 377, 169-172.

488 Kuznetsova, T. G., Starodubtseva, M. N., Yegorenkov, N. I., Chizhik, S. A., Zhdanov, R. I., 2007. Atomic 489 force microscopy probing of cell elasticity. Micron. 38, 824-833.

490 Le Douce, V., Ait-Amar, A., Forouzan far, F., Fahmi, F., Quiel, J., El Mekdad, H., et al., 2016. Improving 491 combination antiretroviral therapy by targeting HIV-1 gene transcription. Expert Opin. Ther. Targets. 20, $492 \quad 1311-1324$.

493 Liu, W., Zhang, J., Rethore, G., Khairoun, K., Pilet, P., Tancret, F., 2014. A novel injectable, cohesive and 494 toughened Si-HPMC (silanized-(hydroxypropyl)methyl cellulose) composite calcium phosphate cement for 495 bone substitution. Acta Biomater. 10, 3335-3345. 
Marquis, M., Alix, V., Capron, I., Cuenot, S., Zykwinska, A., 2016. Microfluidic Encapsulation of Pickering 497 Oil Microdroplets into Alginate Microgels for Lipophilic Compound Delivery. ACS Biomater. Sci. Eng. 2, $498 \quad 535-543$.

499 Marquis, M., Davy, J., Fang, A., Renard, D., 2014. Microfluidics-Assisted Diffusion Self-Assembly: Toward 500 the Control of the Shape and Size of Pectin Hydrogel Microparticles. Biomacromolecules. 15, 1568-1578.

Matalanis, A., McClements, D. J., 2013. Hydrogel microspheres for encapsulation of lipophilic components: Optimization of fabrication \& performance. Food Hydrocoll. 31, 15-25.

Matalanis, A., Griffith Jones, O., McClements, D. J., 2011. Structured biopolymer -based delivery systems for encapsulation, protection, and release of lipophilic compounds. Food Hydrocoll. 25, 1865-1880.

Merian, J., Gravier, J., Navarro, F., Texier, I., 2012. Fluorescent Nanoprobes Dedicated to in Vivo Imaging:

From Preclinical Validations to Clinical Translation. Molecules. 17, 5564-5591.

Morgan, C. E., Wasserman, M. A., Kibbe, M. R., 2016. Targeted Nanotherapies for the Treatment of Surgical

Diseases. Ann. Surg. 263, 900-907.

Moussa, L., Pattappa, G., Doix, B., Benselama, S.-L., Demarquay, C., Benderitter, M., et al., 2017. A biomaterial-assisted mesenchymal stromal cell therapy alleviates colonic radiation-induced damage. Biomaterials. 115, 40-52.

Nguyen, A. H., McKinney, J., Miller, T., Bongiorno, T., McDevitt, T. C., 2015. Gelatin methacrylate microspheres for controlled growth factor release. Acta Biomater. 13, 101-110.

Pagels, R. F., \& Prud'homme, R. K., 2015. Polymeric nanoparticles and microparticles for the delivery of peptides, biologics, and soluble therapeutics. J. Control. Release. 219, 519-535.

Pallicer, J. M., Roses, M., Rafols, C., Bosch, E., Pascual, R., Port, A., 2014. Evaluation of log Po/w values of drugs from some molecular structure calculation software. ADMET \& DMPK. 2, 107-114.

Poon, B., Rittel, D., Ravichandran, G., 2008. An analysis of nano indentation in linearly elastic solids. Int. J.

Popp, I., Del Pozzo, L., Waser, B., Reubi, J. C., Meyer, P. T., 2017. Approaches to improve metabolic stability of a statine-based GRP receptor antagonist. Nucl. Med. Biol. 45, 22-29.

522 Pyka, A., Babuska, M., \& and Zachariasz, M., 2006. A comparison of theoretical methods of calculation of 523 partition coefficients for selected drugs. Acta Pol. Pharm. 63, 159-167. 
524 Rederstorff, E., Weiss, P., Sourice, S., Pilet, P., Xie, F., Sinquin, C., et al., 2011. An in vitro study of two 525 GAG-like marine polysaccharides incorporated into injectable hydrogels for bone and cartilage tissue 526 engineering. Acta Biomater. 7, 2119-2130.

527 Rowe, R. C., Sheskey, P. J., \& Quinn, M. E., 2009. Handbook of Pharmaceutical Excipients Sixth edition. 528 UK, USA: Pharmaceutical Press and the American Pharmacists Association.

529 Rui, M., Qu, Y., Gao, T., Ge, Y., Feng, C., Xu, X., 2017. Simultaneous delivery of anti-miR21 with 530 doxorubicin prodrug by mimetic lipoprotein nanoparticles for synergistic effect against drug resistance in 531 cancer cells. Int. J. Nanomedicine. 12, 217-237.

532 Sekine, T., Yoshida, K., Matsuzaki, F., Yanaki, T., Yamaguchi, M., 2000. A Novel Method for Preparing Oil533 in-Water-in-Oil Type Multiple Emulsions Using Organophilic Montmorillonite Clay Mineral. J. Surfactants 534 Deterg. 2, 309-315.

535 Struillou, X., Rakic, M., Badran, Z., Macquigneau, L., Colombeix, C., Pilet, P., et al., 2013. The association 536 Subbiah, R., Hwang, M. P., Van, S. Y., Do, S. H., Park, H., 2015. Osteogenic/Angiogenic Dual Growth Factor Delivery Microcapsules for Regeneration of Vascularized Bone Tissue. Adv. Healthc. Mater. 4, 1982-92.

Teo, P. Y., Cheng, W., Hedrick, J. L., Yan, Y., 2016. Co-delivery of Drugs and Plasmid DNA for Cancer 541 Therapy. Adv. Drug Deliv. Rev. 98, 41-63.

542 Ulbrich, K., Hola, K., Subr, V., Bakandritsos, A., Tucek, J., Zboril, R., 2016. Targeted Drug Delivery with 543 Polymers and Magnetic Nanoparticles: Covalent and Noncovalent Approaches, Release Control, and Clinical 544 Studies. Chem. Rev. 116, 5338-5431.

545 Vinatier, C., Gauthier, O., Fatimi, A., Merceron, C., Masson, M., Moreau, A., et al. (2009). An Injectable 546 Cellulose-Based Hydrogel for the Transfer of Autologous Nasal Chondrocytes in Articular Cartilage Defects. 547 Biotechnology and Bioengineering, 102 (4), 1259-1267.

548 Vinatier, C., Magne, D., Moreau, A., Gauthier, O., Malard, O., Vignes-Colombeix, C., et al., 2007. 549 Engineering cartilage with human nasal chondrocytes and a silanized (hydroxypropyl)methyl cellulose 550 hydrogel. J. Biomed. Mater. Res. A, 80A, 66-74. 
551 Vinatier, C., Mrugala, D., Jorgensen, C., Guicheux, J., \& Noël, D. (2009). Cartilage engineering: a crucial 552 combination of cells, biomaterials and biofactors. Trends in Biotechnology, 27 (5), 307-314.

553 Weber, M., Zoschke, C., Sedighi, A., Fleige, E., Haag, R., Schäfer-Korting, M., 2014. Free Energy 554 Simulations of Cargo-Carrier Interactions for Core-Multishell Nanotransporters. J. Nanomed. Nanotechnol., 5, 5551000234.

556 Wollenweber, C., Makievski, A., Miller, R., Daniels, R., 2000. Adsorption of (hydroxypropyl)methyl 557 cellulose at the iquid/liquid interface and the effect on emulsion stability. Colloids Surf. A Physicochem. Eng. 558 Asp. 172, 91-101.

559 Wu, S., Yang, X., Li, W., Du, L., Zeng, R., Tu, M., 2017. Enhancing osteogenic differentiation of MC3T3-E1 560 cells by immobilizing RGD onto liquid crystal substrate. Mater. Sci. Eng. C Mater. Biol. Appl. 71, 973-981.

561 Zhang, J., Liu, W., Gauthier, O., Sourice, S., Pilet, P., Rethore, G., et al., 2016. A simple and effective 562 approach to prepare injectable macroporous calcium phosphate cement for bone repair: Syringe-foaming using 563 a viscous hydrophilic polymeric solution. Acta Biomate. 31, 326-338.

564 Zhao, C.-X. (2013). Multiphaseflow microfluidics for the production of single or multiple emulsions for drug 565 delivery. Adv. Drug Deliv. Rev. 65, 1420-1446. 


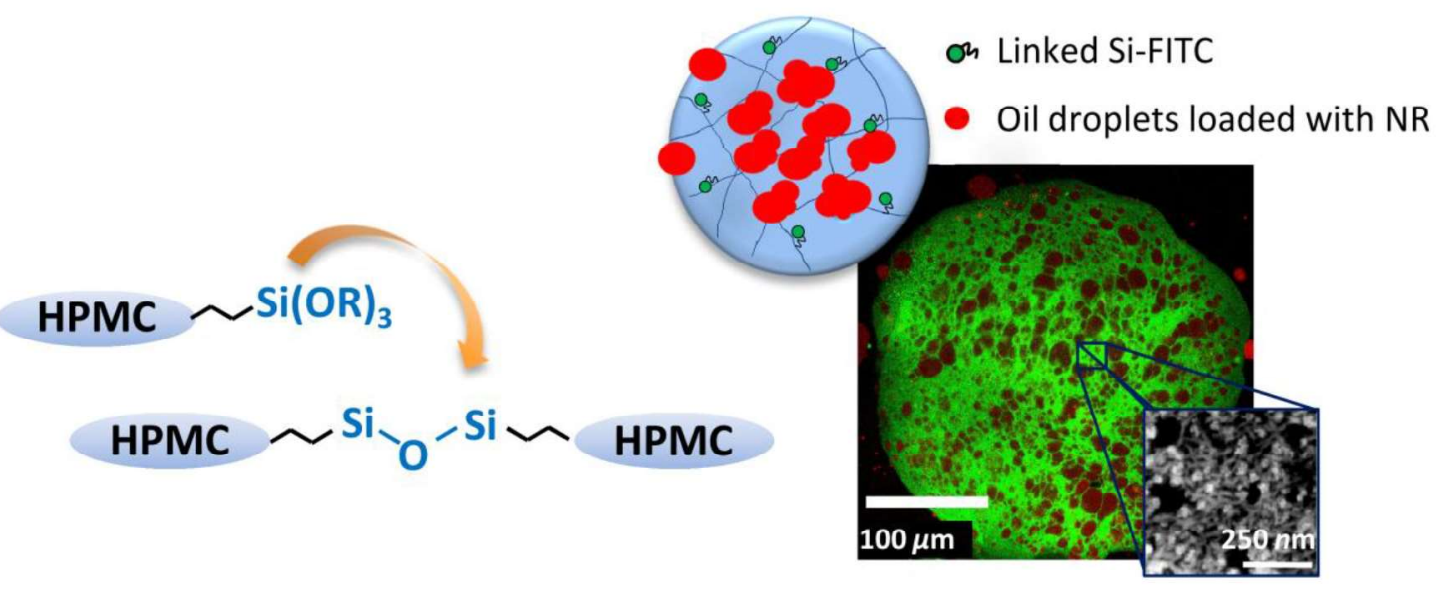


Scheme 1: This scheme represents the protocol of preparation of FMGs and BPMGs based on the solgel reaction and a templating emulsification process. The $\mathrm{pH}$ and the temperature are the main parameters that control the chemical cross-linking reaction, leading to formation of Si-O-Si bonds. The Si-HPMC network could be functionalized with a model molecule, such as Si-FITC in FMGs. Oil compartments for lipophilic molecules encapsulation, were trapped in the BPMGs.

Table 1: Interfacial behavior of Si-HPMC versus HPMC.

Figure 1: Emulsions W/O of Si-HPMC (A) leads to the formation of the microgels only after neutralization and increasing the temperature to $45^{\circ} \mathrm{C}(\mathrm{B})$, while no spherical morphologies were obtained at $\mathrm{pH} 12$ and room temperature (C). HPMC W/O emulsion (D) did not give any structures after $\mathrm{pH}$ and temperature treatment $\left(\mathrm{pH}\right.$ neutralization, $\left.\mathrm{T}^{\circ} \mathrm{C}=45^{\circ} \mathrm{C}\right)(\mathrm{E}) .(\mathrm{bar}=400 \mu \mathrm{m})$

Figure 2: Optimization of the size distribution of the microgels by adjusting the water phase in oil feeding rate, for the microgels $\mathrm{W} / \mathrm{O}(\mathrm{A})$ and $\mathrm{BPMGs} \mathrm{O} / \mathrm{W} / \mathrm{O}(\mathrm{B}, \mathrm{C}, \mathrm{D})$. The red curve is the Log Normal fit. $($ bar $=400 \mu \mathrm{m})$

Table 2: Loading efficiency of Si-Fluor determined in bulk hydrogel $\left(\mathrm{C}_{\mathrm{I}}=\right.$ initial weight concentration; $\mathrm{C}_{\mathrm{L}}=$ linked weight concentration).

Figure 3: (A) Optical microscopy of the first dispersion $\mathrm{O} / \mathrm{W}(\mathrm{O}=$ sesame oil; $\mathrm{W}=\mathrm{Si}-\mathrm{HPMC}$ $3 \mathrm{wt} \%$, (B) Size distribution of the oil droplets (log normal fitting curve), (C) Phase separation between the oil droplets phase (Nile Red labeling) dispersed in Si-HPMC 3 wt\% sol labeled with Si-Fluor by LCSM, (D) SEM of the freeze-dryed O/W emulsion.

Table 3: Loading efficiency of Nile red in the oily phase, effect on the size distribution of the oil droplets and of the BPMGs

Figure 4: SEM observations of (A) hydrated and (B) freeze-dried BPMGs, their internal phase separation (C) between the hydrophilic and the lipophilic phases by LSCM, and the topography (D) of the Si-HPMC network of dried BPMGs determined by AFM.

Figure 5: AFM nanoindentation on FMGs (black) and BPMGs (red) reporting the Force (N) to indentation distance fitted by the Sneddon model.

Figure 6: Effect of physiological and extreme $\mathrm{pH}$ on the extraction and release evaluation of the model drugs from the BPMGs.

Figure 7: Mechanical properties evolution of BPMGs with their optical microscopy (A, C, E) and epifluorescence (B, D, F) observations at different times of incubation : (A, B) BPMGs at $\mathrm{D}_{0},(\mathrm{C}, \mathrm{D})$ after 17 days in PBS $60 \mathrm{mM} \mathrm{pH} \mathrm{7.4,} \mathrm{(E,} \mathrm{F)} \mathrm{after} 17$ days in $\mathrm{HCl}$ pH 1.5. bar $=200 \mu \mathrm{m}$ 


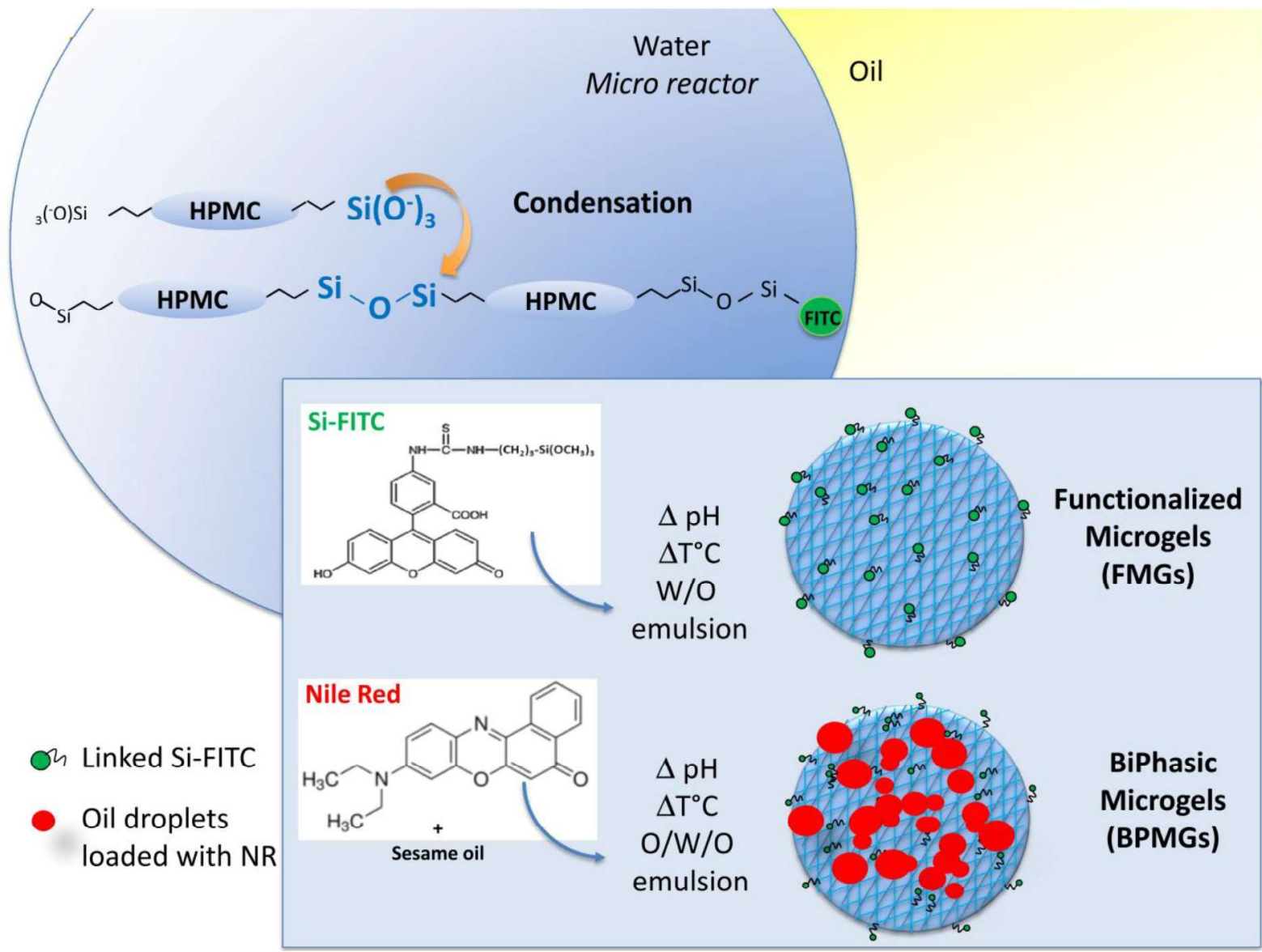


Table 1

\begin{tabular}{cccc}
\cline { 2 - 4 } & $\Gamma\left(\mathrm{mol} / \mathrm{m}^{2}\right)$ & CAC $(\mathrm{M})$ & $\mathrm{A}_{\text {Gibbs }}\left(\mathrm{nm}^{2}\right)$ \\
\hline HPMC 2910 [38] & $6.910^{-6}$ & $1.8210^{-7}$ & 0.24 \\
Si-HPMC & $5.410^{-6}$ & $5.4010^{-8}$ & 0.31 \\
\hline
\end{tabular}


Figure 1

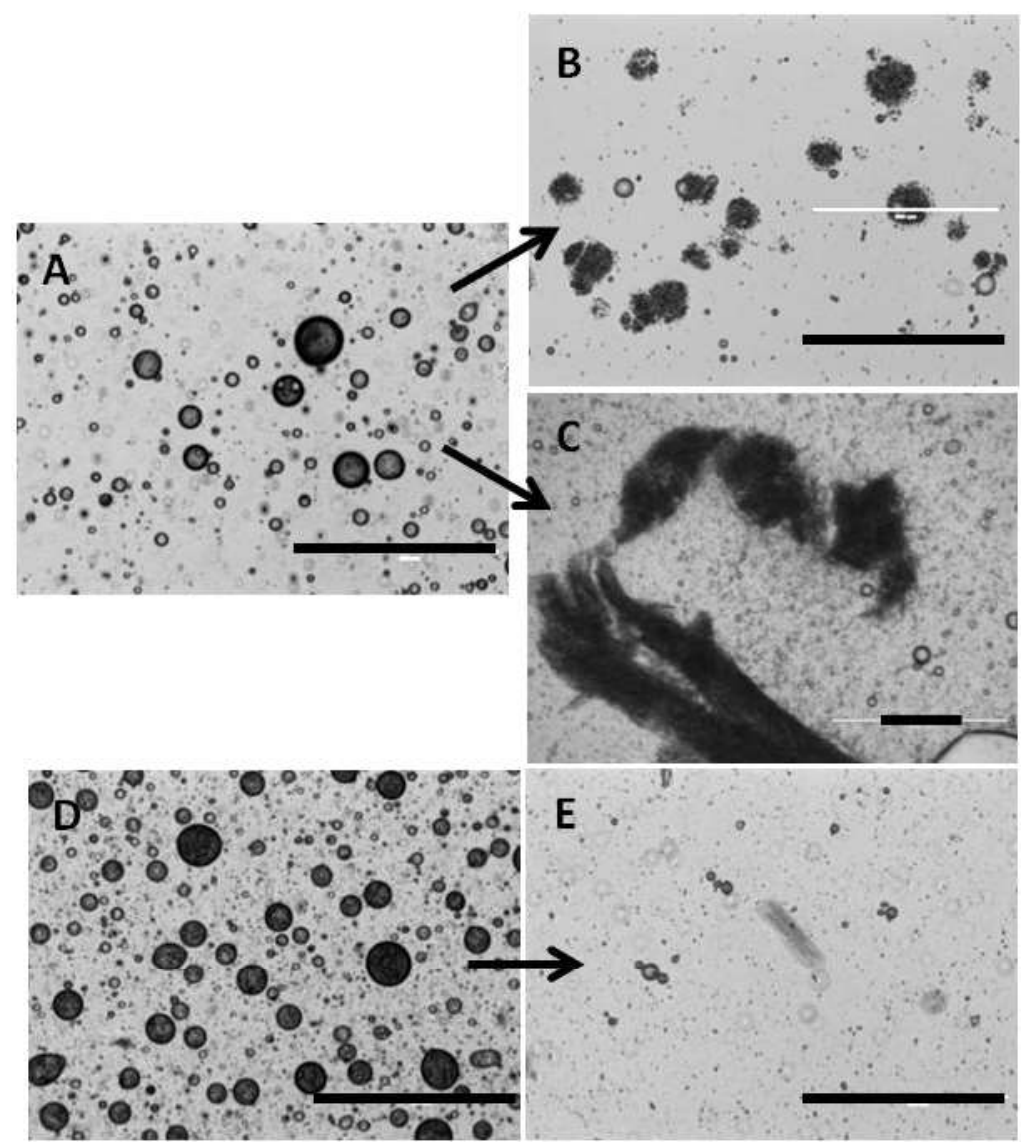



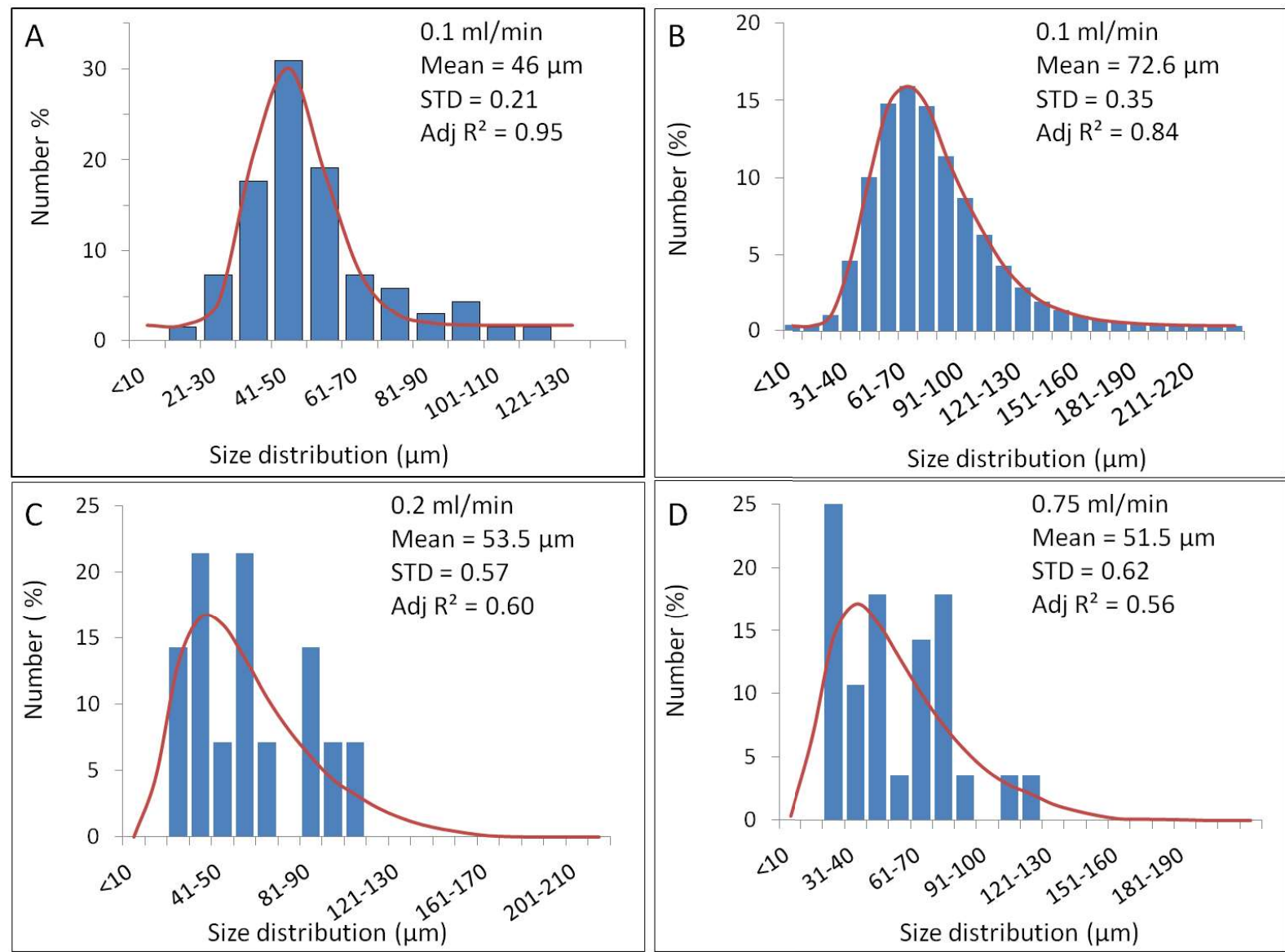

$0.75 \mathrm{ml} / \mathrm{min}$

Mean $=53.5 \mu \mathrm{m}$

STD $=0.57$

Adj $R^{2}=0.60$

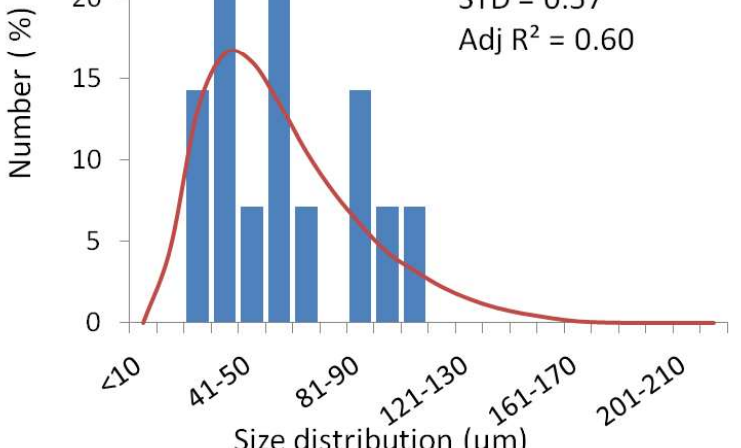

Size distribution ( $\mu \mathrm{m})$ 
Table 2

\begin{tabular}{cc}
\hline $\mathbf{C}_{\mathbf{i}}$ & $\mathbf{C}_{\mathbf{L}}$ \\
$(\boldsymbol{\mu g} / \mathbf{g}$ HPMC-Si $)$ & $(\boldsymbol{\mu g} / \mathbf{g}$ HPMC-Si $)$ \\
\hline 0.09 & 0.09 \\
0.45 & 0.44 \\
1.12 & 1.12 \\
2.23 & 0.73 \\
11.12 & 0.80 \\
\hline
\end{tabular}


Figure 3

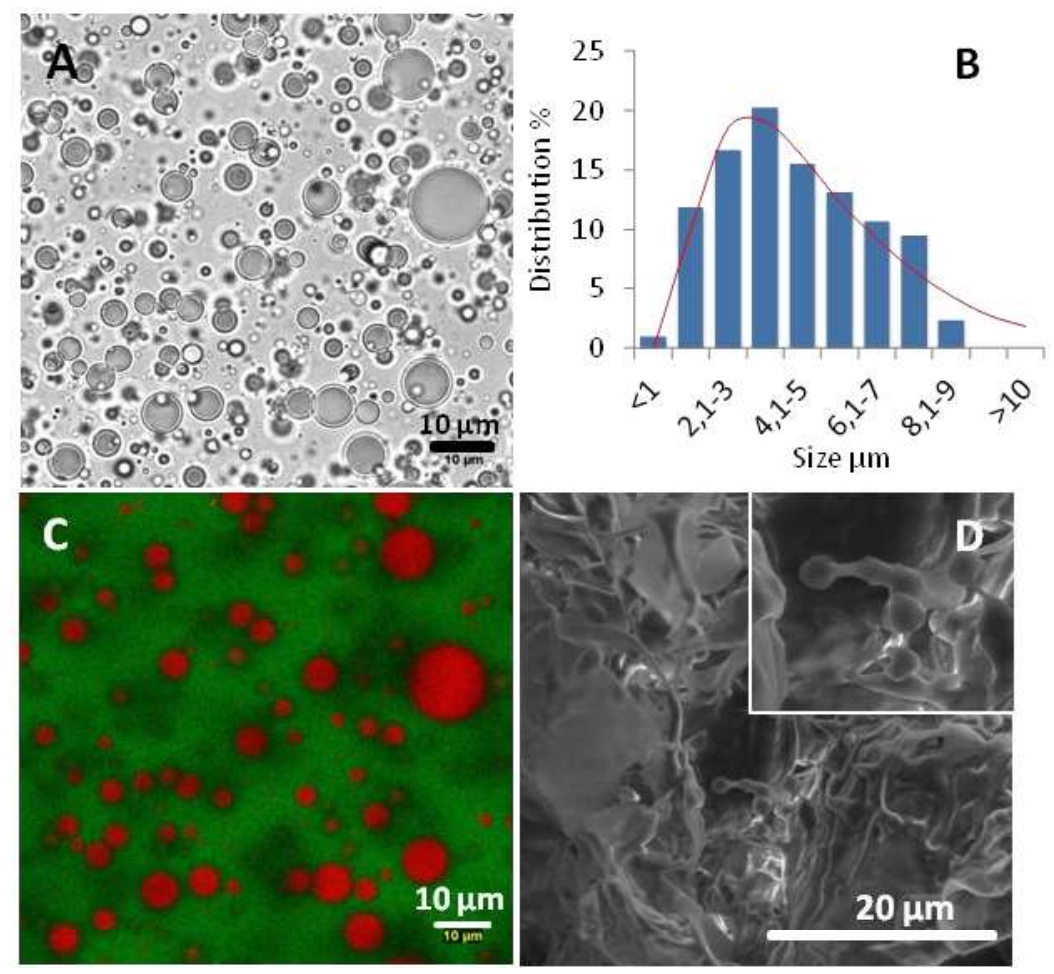


Table 3

\begin{tabular}{ccccc}
\hline Concentration in the oil & \multicolumn{2}{c}{ O/W oil droplets } & \multicolumn{2}{c}{ BPMGs } \\
\cline { 2 - 5 } phase $(\boldsymbol{\mu g} / \mathbf{m l})$ & Size $(\boldsymbol{\mu m})$ & STD (\%) & Size $(\boldsymbol{\mu m})$ & STD (\%) \\
\hline 7.0 & 9.4 & 0.40 & 84.2 & 25 \\
25.0 & 4.1 & 0.15 & 81.1 & 24 \\
62.0 & 7.3 & 0.20 & 127.7 & 35 \\
$\geq 124.0$ & 5.7 & 0.10 & No BPMGs & No BPMGs \\
\hline
\end{tabular}


Figure 5

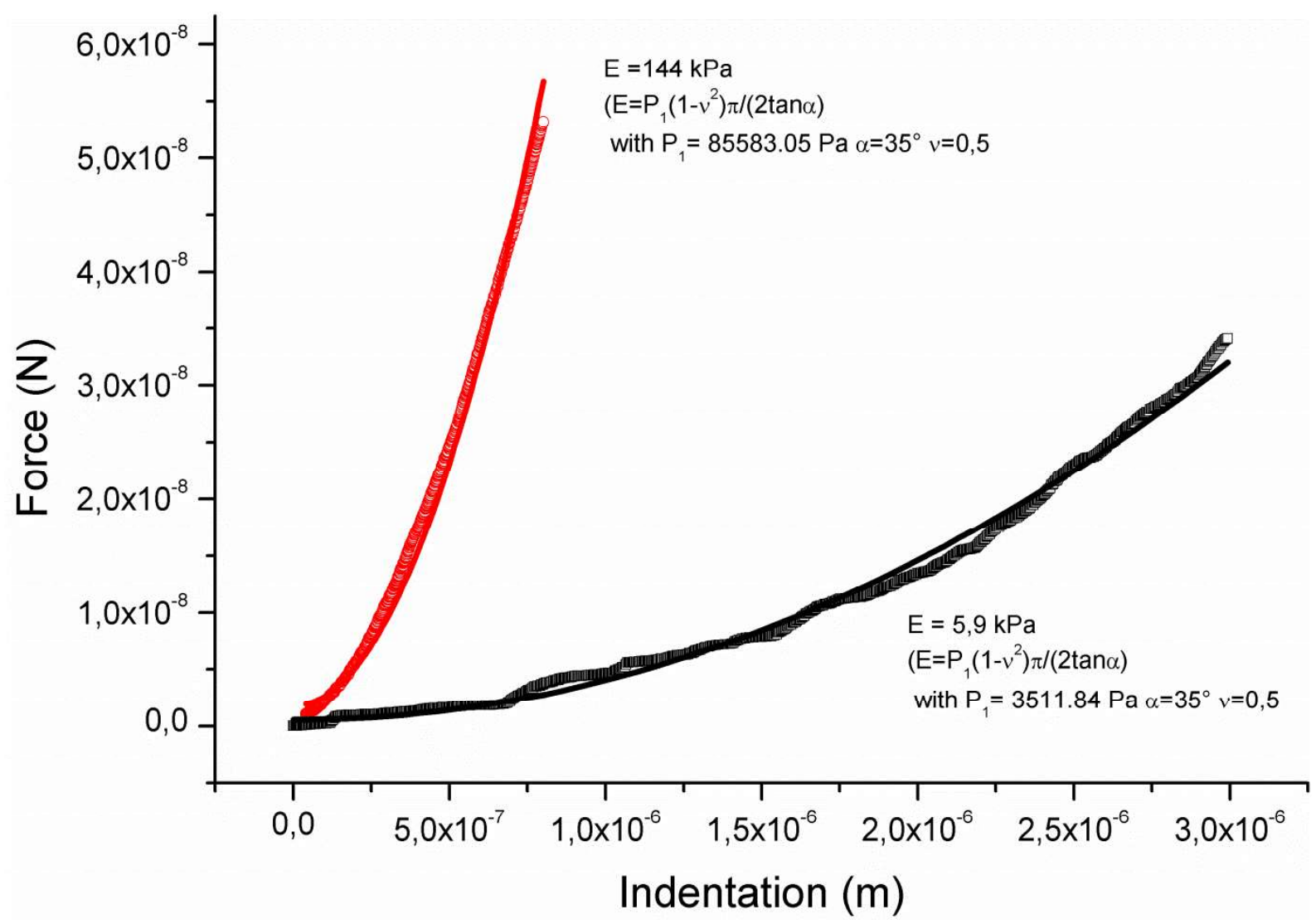


Figure 6

Si-Fluor Nile red

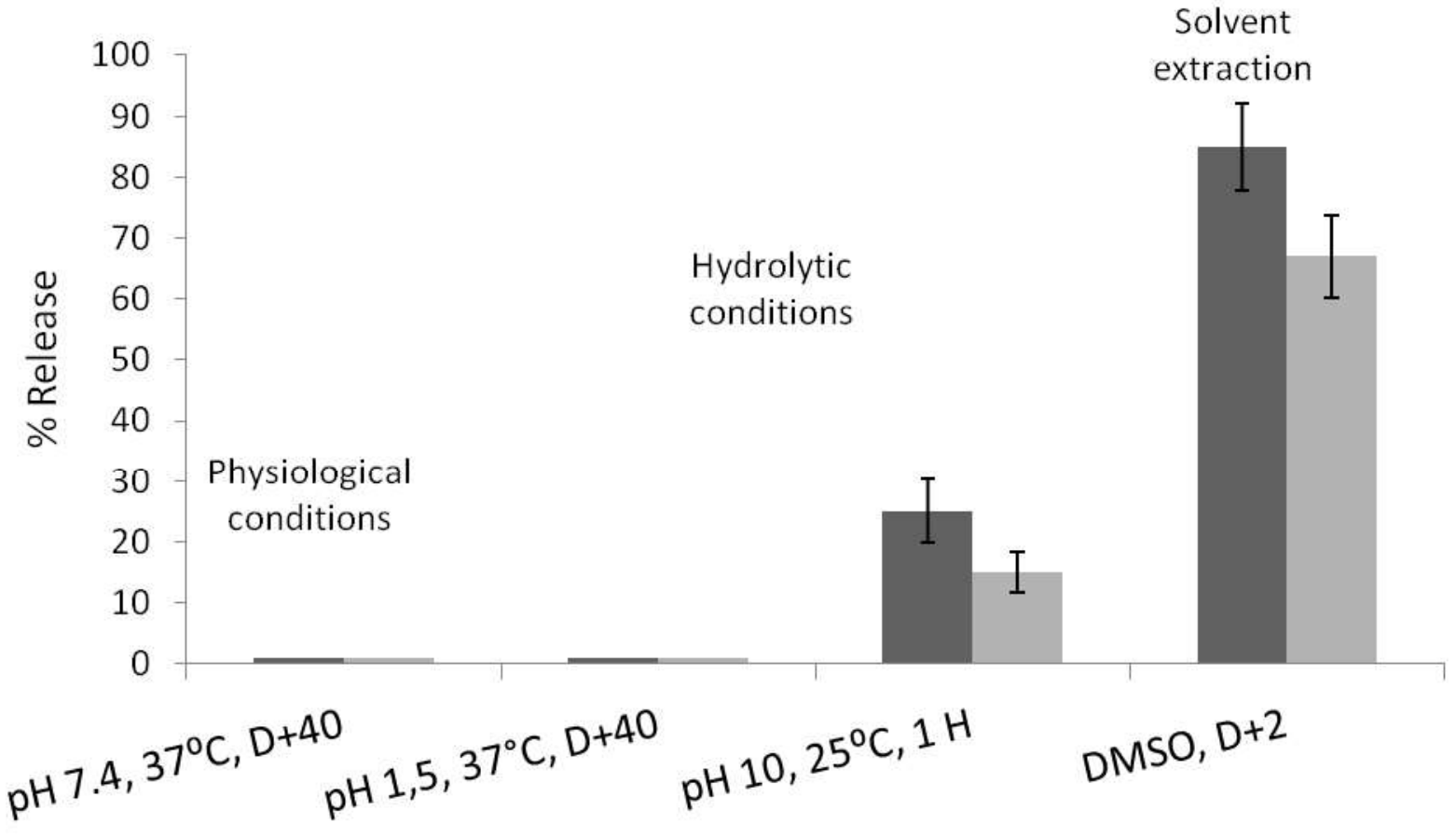



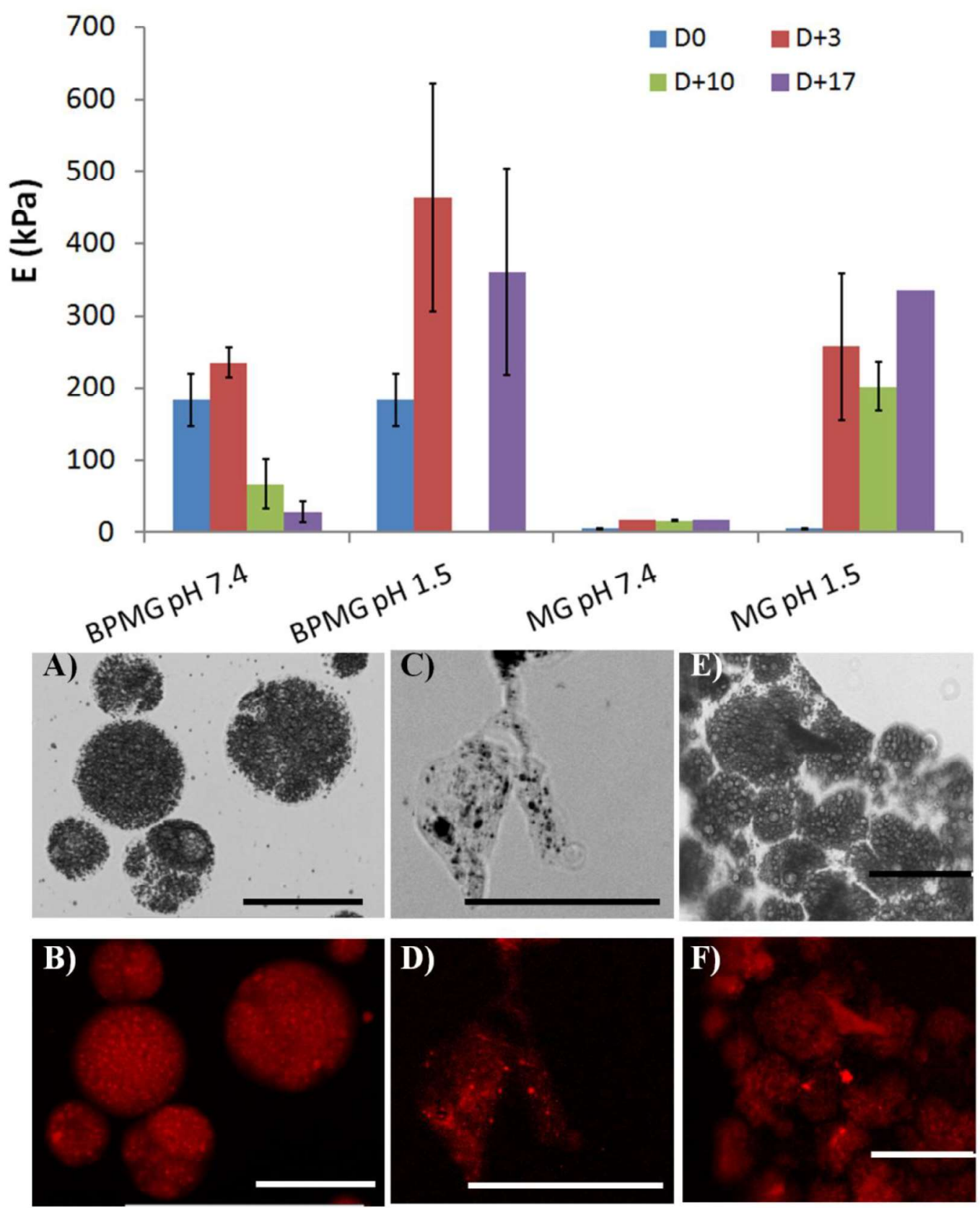